\title{
Stochastic cooperative advertising in a manufacturer-retailer decentralized supply channel
}

\author{
Peter E. Ezimadu ${ }^{1} \cdot$ Chukwuma R. Nwozo $^{2}$
}

Received: 28 May 2015/Accepted: 20 July 2016/Published online: 1 August 2016

(C) The Author(s) 2016. This article is published with open access at Springerlink.com

\begin{abstract}
This work considers cooperative advertising in a manufacturer-retailer supply chain. While the manufacturer is the Stackelberg leader, the retailer is the follower. Using Sethi model it models the dynamic effect of the manufacturer and retailer's advertising efforts on sale. It uses optimal control technique and stochastic differential game theory to obtain the players' advertising strategies and the long-run value of the awareness share. Further, it models the relationship between the payoffs of both players and the awareness share. The work shows that with the provision of subsidy the retail advertising effort increases while the manufacturer's advertising effort reduces. It further shows that the total channel payoff is higher for subsidised retail advertising. However, the subsidy can only be possible if the rate of growth of the manufacturer's payoff is twice higher than that of the retailer.
\end{abstract}

Keywords Supply chain - Cooperative advertising . Stochastic differential game $\cdot$ Subsidy $\cdot$ Sethi model . Optimal control

Chukwuma R. Nwozo

crnwozo@yahoo.com

Peter E. Ezimadu peterezimadu@yahoo.com

1 Department of Mathematics and Computer Science, Delta State University, Abraka, Nigeria

2 Department of Mathematics, University of Ibadan, Ibadan, Nigeria

\section{Introduction}

Studies have shown that in non-cooperative relationships, the leader has manipulative power to control the follower. Having estimated the follower based on the available information and deduced his possible reactions, the leader then decides the first move (moves first), and then prescribes the behaviour of the follower (Yue et al. 2006). Since the manufacturer has the capacity to control the channel in a traditional setting, he acts as the channel leader in a manufacturer-retailer supply chain.

First we distinguish between local and national advertising since this will aid our understanding of cooperative advertising. The aim of local advertising is to induce shortterm purchase through the local media. National advertising aims at building a long-term image for the company or for some of its major products (Young and Greyser 1983; Houk 1995). Local advertising is often price oriented because its goal is to ensure immediate purchase. The emphasis on national advertising is to create more favourable product attitudes. There is a significant difference between the costs of both types of advertising. This is because the retailer's means of advertising is the local media which operates at lower costs. He also has better local market information. Thus the importance of both types of advertising cannot be over emphasized because of their distinct and significant roles. Cooperative advertising is an arrangement where the manufacturer bears some or all the costs of local advertising incurred by the retailer for good(s) produced by the manufacturer.

The cooperative advertising literature can be categorized into three groups: static, dynamic and stochastic models. Berger (1972) was the first to consider static model on cooperative advertising as discount given by the manufacturer to the retailer as an advertising allowance. Dant 
and Berger (1996) extended the Berger model to include cooperative advertising decision in franchising systems where demand is uncertain and both channel members differ on their expected sales. Huang et al. (2002) argued that embarking on static examination of cooperative advertising is justified since promotion effects do not last long compared to advertising, and is primarily a driver of short term sales. However, empirical results in Naik et al. (2005), Chintagunta and Vilcassim (1994) and Fruchter and Kalish (1998) suggest that dynamic models are superior in examining cooperative advertising.

By considering the manufacturer as the Stackelberg leader in an extended Nerlove and Arrow (1962) framework, Jørgensen et al. (2000) employed Stackelberg differential game to model the relationship between the manufacturer and the retailer in a dynamic setting. For more references on dynamic cooperative differential game see Karray and Zaccour (2005), Jørgensen et al. (2003) and He et al. (2011).

He et al. (2009) considered a manufacturer-retailer Stackelberg game on cooperative advertising using the stochastic model proposed by Sethi (1983). Specifically, only the retailer is involved in advertising with advertising support in the form of subsidy from the manufacturer. Other recent works on cooperative advertising include $\mathrm{He}$ et al. (2014), Aust (2015) and Giri et al. (2015).

This work extends $\mathrm{He}$ et al. (2009) by considering the direct involvement of the manufacturer in cooperative advertising. Thus while the retailer is involved in local advertising, the manufacturer subsidises retail advertising and engages in national advertising.

As we will observe later, part of the interest of this work is to consider the performance of the supply chain. Supply chain is a system of manufacturer(s) and retailer(s) involved in the movement of goods and/or services from the producer to the consumer. Recently supply chain witnessed a number of contributions in advertising and related fields. Taleizadeh and Charmchi (2015) studied a two-echelon supply chain consisting of one manufacturer (the Stackelberg leader) and one retailer (the Stackelberg follower) with two complementary goods. They showed that manufacturer's and retailer's profits decrease when the complementary degree between two products is large. In analysing the pricing decisions of the members of a supply chain for complementary and substitute products with different market powers, Esmaeilzadeh and Taleizadeh (2016) considered hierarchical relationship where the manufacturers are the Stackelberg leaders and the retailers are the followers. Heydari and Norouzinasab (2015) studied a two-level discounted model for coordinating a decentralized supply chain. They showed that the proposed two-level discount policy is suitable for coordinating the channel. Using game theory Esmaeili et al. (2015) modeled the conflicts between countries and their common resources. Also Mahmoudi et al. (2014) used game theory to propose a model that will be useful to the government in determining optimal taxes and subsidies. To create more valuable manufacturing and business operations, Golrizgashti (2014) developed a balanced approach which is helpful in measuring supply chain performance. Additional works on supply chain include Kumar et al. (2013) and Rao et al. (2013).

\section{Model formulation}

As regards advertising expenditures, studies in the literature can be categorized into two. There are those that do not differentiate between the manufacturer's advertising expenditure and retailer's advertising expenditure in the determination of the value of the payoff function (Berger 1972; Little 1979; Tull et al. 1986; Dant and Berger 1996; He et al. 2009, 2011). The other category distinguishes between both types of advertising. Their argument is that both types of advertising expenditures can influence sales and eventually the payoff functions differently, and as such should be assessed differently (Jørgensen et al. 2000; Huang et al. 2002). We align with the school of thought that views both types as distinct.

To increase the awareness share (which eventually leads to the sale of the manufacturer's product), the retailer decides the local advertising effort $a_{R}(t)$, while the manufacturer decides the national advertising effort $a_{M}(t)$ and retail advertising participation rate $\lambda(t)$.

In the literature it is common to assume a quadratic cost function (Deal 1979; Chintagunta and Jain 1992; Jørgensen et al. 2000; Prasad and Sethi 2004; He et al. 2009, 2011). This implies increasing marginal cost of advertising. Towing this line, we let the cost of advertising to be quadratic in the manufacturer and retailer's advertising efforts $a_{M}(t)$ and $a_{R}(t)$ respectively. Thus $\lambda a_{R}(t)^{2}+a_{M}(t)^{2}$ and $(1-\lambda) a_{R}(t)^{2}$ represent the manufacturer and retailer's advertising expenditures respectively.

\section{Dynamics of the awareness share}

To model the dynamic effect of advertising on sales we shall use the Sethi advertising model (Sethi 1983).

$$
\begin{aligned}
& \mathrm{d} y(t)=[\beta a(t) \sqrt{1-y(t)}-k y(t)] \mathrm{d} t+\sigma(y(t)) \mathrm{d} z(t) \\
& y(0)=y_{0} \in[0,1], \quad t \geq 0,
\end{aligned}
$$

where $a(t)$ is the advertising effort, $y(t)$ is the market share, $y$ is the initial condition, $\beta$ is the advertising effectiveness parameter, $k$ is the decay parameter. It is a modification of 
the Vidale-Wolfe advertising model (Vidale and Wolfe 1957). Different forms of this model have been considered. The model and its competitive extensions have been broadly used in the literature (Sorger 1989; Chintagunta and Vilcassim 1992; Chintagunta and Jain 1995; Prasad and Sethi 2004; Bass et al. 2005; Naik et al. 2008; Erickson 2009; Prasad and Sethi 2009; Erickson 2009; He et al. 2009), and some of these extensions have also been validadted empirically (Chintagunta and Vilcassim 1992; Chintagunta and Jain 1995; Naik et al. 2008; Erickson 2009), thus ensuring its applicability. This model is given by

$$
\begin{gathered}
\mathrm{d} y(t)=\left[\alpha\left(a_{R}(t)+a_{M}(t)\right) \sqrt{1-y(t)}-k y(t)\right] \mathrm{d} t+\sigma(y(t)) \mathrm{d} z(t) \\
y(0)=y_{0} \in[0,1], \quad t \geq 0,
\end{gathered}
$$

where $y(t)$ is the awareness share representing the fraction of the market aware of the product. $y_{0}$ is the initial proportion of the market aware of the product, $\alpha$ is the response constant. It measures the advertising effectiveness. Thus $\alpha \in[0,1] . k$ is the decay constant. It measures the rate at which potential consumers are lost due to background competition, forgetfulness, product obsolesce and so on. $\sigma(y(t))$ represents a variance term and $z(t)$, represents a standard Wiener process on the underlying probability space $(\Omega, \Im, \mathrm{P}) . a_{R}(t)$ and $a_{M}(t) \geq 0$ are nonanticipative with respect to the Wiener process $z(t)$. These are stochastic processes.

Considering (2) we see that the awareness share dynamics is affected linearly by both the retail advertising effort $a_{R}(t)$ of the retailer and the national advertising effort $a_{M}(t)$ of the manufacturer. These are respectively, the square roots of the retail advertising expenditure $a_{R}(t)^{2}$ and manufacturer's advertising expenditure $a_{M}(t)^{2}$. Thus they are concave functions for the advertising expenditures. Both local and national advertising efforts focus on the fraction of the population of end-users (consumers) who are unaware of the product.

Despite the stochastic disturbances the awareness share is bounded between 0 and 1 with the assumption that the function $\sigma:(0,1) \rightarrow \mathbb{R}$ is continuous and Lipschitz on every subinterval of $(0,1)$, and $a(t), a_{M}(t) \geq 0$ and $\sigma(0)=\sigma(1)=0$. This gives a strictly positive drift when the awareness share is 0 and a strictly negative drift when it is 1 . Then the solutions of (2) have 0 and 1 as natural boundaries (Gihman and Skorohod 1972), with $y(0)=y_{0} \in[0,1]$, that is $y(t) \in(0,1)$ almost surely.

We observe that (2) is an extension of (1) with the introduction of the manufacturer's advertising effort $a_{M}(t)$. Based on this extension we will compare the effect of subsidy on the local advertising effort $a_{R}(t)$ and national advertising effort $a_{M}(t)$, and the resulting effect on the awareness share and the players' payoffs. Further we will compare channel performances for subsidised and unsubsidised retail advertising.

Before proceeding further, it is pertinent to note that in this work we restrict our attention to feedback Stackelberg solutions where the optimal policy, in general, depends on the current state and time (Basar and Olsder 1999; He et al. 2009, 2011).

\section{The sequence of events in the leader-follower relationship model}

The events in this game will evolve as follows. The manufacturer takes the first step by unveiling his feedback national advertising effort $a_{M}(y) \geq 0$ and the feedback participation rate $\lambda(y) \in[0,1]$ on retail advertising.

In reaction to the manufacturer's declarations, the retailer then decides the advertising effort $a_{R}(t)$. This is achieved by solving the optimal control problem

$$
V^{R}(y)=\max _{\substack{a_{R}(t) \geq 0 \\ t \geq 0}}\left\{\mathbb{E} \int_{0}^{\infty} \mathrm{e}^{-\eta t}\left\{m y(t)-a_{R}(t)^{2}+\lambda(t) a_{R}(t)^{2}\right\} \mathrm{d} t\right\}
$$

subject to (2), where $\mathbb{E}$ is the expectation operator; $\eta$ is the discount rate and $m$ is the retailer's margin. The optimal value of the retailer's discounted total profit $V^{R}(y)$ depends only on the initial value $y_{0}$ at time $t=0$. In anticipation of the retailer's reaction the manufacturer incorporates same (the retailer's reactions) into his control problem, and solves for his national advertising effort $a_{M}(y)$ and participation rate $\lambda(y)$. Thus we have that

$$
V^{M}(y)=\max _{\substack{a_{M}(t) \geq 0, 0 \leq \lambda(t) \leq 1}}\left\{\mathbb{E} \int_{0}^{\infty} \mathrm{e}^{-\eta t}\left\{M y(t)-\lambda(t) a_{R}\left(y(t) \mid \lambda(t), a_{M}(t)\right)^{2}-a_{M}(t)^{2}\right\} \mathrm{d} t\right\},
$$

subject to

$$
\begin{aligned}
\mathrm{d} y(t)= & {\left[\alpha\left(a_{R}\left(y(t) \mid \lambda(t), a_{M}(t)\right)+a_{M}(t)\right) \sqrt{1-y(t)}-k x(t)\right] \mathrm{d} t } \\
& +\sigma(y(t)) \mathrm{d} z(t) \\
& y(0)=y_{0} \in[0,1], \quad t \geq 0 .
\end{aligned}
$$

\section{The players' advertising strategies and subsidy}

First we solve the optimal control problems (2)-(5) for the retailer's best response to the manufacturer's policy, the manufacturer's advertising and subsidy decisions. 
Theorem 3.1 Given the manufacturer's advertising effort $a_{M}$ and participation rate $\lambda$, then the retail advertising effort is given by

$a_{R}\left(y \mid \lambda, a_{M}\right)=\frac{V_{y}^{R} \sqrt{1-y}}{2(1-\lambda(y))}$,

while the manufacturer's advertising effort is given by

$a_{M}(y)=\frac{\alpha V_{y}^{M} \sqrt{1-y}}{2}$,

and the participation rate is

$\lambda=\frac{2 V_{y}^{M}-V_{y}^{R}}{2 V_{y}^{M}+V_{y}^{R}}$.

Proof The proof is in "Appendix 1".

Observe from (6) and (7) that the advertising efforts $a_{R}$ and $a_{M}$ depend on the level of awareness $y$. That is, in course of advertising, the players consider the fraction of the market that is aware of the product. This is because the aim of advertising is to gain a good fraction of the market. Thus it is proper for the efforts to be functions of those who are aware of the product.

Now, considering the term $2(1-\lambda(y))$ we observe that the subsidy from the manufacturer must be constrained to be $\lambda(y) \in[0,1)$. This is because by letting $\lambda(y)=1, a_{R}$ will become unbounded. This is not ideal since it is not possible for the retailer to spend such an extremely large sum on advertising. Thus knowing that the retailer will not want to spend such a very large sum on advertising, it would be unwise for the manufacturer to completely subsidize retail advertising. Hence, the idea of subsidizing only a fraction is quite ideal. Further we note that by engaging in national advertising and complete subsidisation of retail advertising effort the manufacturer bears the burden of the entire supply chain. This is not healthy for the chain.

Further it is pertinent to note that the presence of $V_{y}^{R}$ and $V_{y}^{M}$ in (6) and (7) mean that the players expend efforts in proportion to the rate at which their individual payoffs are growing. Thus as the payoffs increase the advertising efforts also increase.

Finally (8) shows that the provision of subsidy can only be possible if the rate of increase of the manufacturer's payoff is twice greater than the rate of increase of the retailer's payoff.

\section{The retailer and manufacturer's advertising policies and payoff when no subsidy is provided}

Now, there are two types of equilibria. The first considers the situation where the manufacturer does not provide any subsidy for retailer advertising. We call this the no cooperative equilibrium. In the second case, the manufacturer subsidises retail advertising. This is called a cooperative equilibrium. We state these in Theorems 4.1 and 4.2 respectively

\section{Feedback Stackelberg equilibrium for unsubsidised retail advertising}

Theorem 4.1 Suppose the retail advertising effort is unsubsidized so that $\lambda=0$, then there is a unique feedback Stackelberg equilibrium $\left(a_{R}^{*}, a_{M}^{*}\right)$ given by

$a_{R}^{*}(y)=\frac{\alpha G_{R} \sqrt{1-y}}{2}$,

$a_{M}^{*}(y)=\frac{\alpha G_{M} \sqrt{1-y}}{2}$,

with the value functions given by

$V^{R}(y)=H_{R}+G_{R} y$,

$V^{M}(y)=H_{M}+G_{M} y$,

and the condition for the manufacturer not to provide any subsidy to support the retail advertising effort, is that $2 G_{M} \leq G_{R}$, where

$G_{R}=\frac{4 M_{R}}{4(k+\eta)+\alpha^{2}\left(G_{R}+2 G_{M}\right)}$,

$G_{M}=\frac{4 M_{M}}{4(k+\eta)+\alpha^{2}\left(2 G_{R}+G_{M}\right)}$,

$H_{R}=\frac{\alpha^{2} G_{R}}{4 \eta}\left[G_{R}+2 G_{M}\right]$

$H_{M}=\frac{\alpha^{2} G_{M}}{4 \eta}\left[2 G_{R}+G_{M}\right]$.

Proof The proof is in "Appendix 2".

$V^{R}(y)$ is the value function of the retailer. (11) shows that it gives the payoff for a given fraction of the market $y$. Note that $G_{R}$ is the rate at which this value function (payoff) is growing. It therefore follows that the retailer's focus will be on how to improve on $G_{R}$. Looking at (13) we observe that this can be done in three ways. First, by improving on his margin, the quantity in (13) will certainly increase. Thus by increasing his margin $M_{R}$, he is in a good position to increase the rate of growth of his value function. Secondly, by being foresighted he will tend to reduce his discount rate to the lowest possible value. Thirdly, is to work towards ensuring that the decay rate is also as small as possible. The rate of forgetfulness can be reduced by employing methods that ensure that the knowledge of the need and importance of the product remain indelible in the mind of the consumer. This same explanation also goes for the manufacturer's payoff. 
From (15) and (16) we observe that $H_{R}$ and $H_{M}$ depend much on the advertising effectiveness and discount rate. By being foresighted and with a higher advertising effectiveness, these quantities will increase.

\section{Feedback Stackelberg equilibrium for subsidised retail advertising}

Theorem 4.2 Suppose the retail advertising effort is subsidized so that $\lambda>0$, then there is a unique feedback Stackelberg equilibrium $\left(a_{R}^{*}, a_{M}^{*}, \lambda^{*}\right)$ given by

$a_{R}^{*}(y)=\frac{\alpha\left(2 G_{M}+G_{R}\right) \sqrt{1-y}}{4}$,

$a_{M}^{*}(y)=\frac{\alpha G_{M} \sqrt{1-y}}{2}$,

$\lambda^{*}=\frac{2 G_{M}-G_{R}}{2 G_{M}+G_{R}}$,

with the value functions given by

$$
\begin{aligned}
& V^{R}(y)=H_{R}+G_{R} y, \\
& V^{M}(y)=H_{M}+G_{M} y,
\end{aligned}
$$

where

$G_{R}=\frac{8 M_{R}}{\alpha^{2}\left(6 G_{M}+G_{R}\right)+8(k+\eta)}$,

$G_{M}=\frac{16 M_{M}-\alpha^{2} G_{R}^{2}}{4\left(\alpha^{2}\left(2 G_{M}+G_{R}\right)+4(k+\eta)\right)}$,

$H_{R}=\frac{\alpha^{2} G_{R}\left[6 G_{M}+G_{R}\right]}{8 \eta}$,

$H_{M}=\frac{\alpha^{2}\left[4 G_{M}\left(2 G_{M}+G_{R}\right)+G_{R}^{2}\right]}{16 \eta}$.

Proof Proof is in "Appendix 3".

As in the unsubsidized case, $G_{M}$ and $G_{R}$ can be improved on by increasing the margins, being foresighted, reducing the rate of forgetfulness and improving on the advertising effectiveness. Further, similar explanations go for $H_{R}$ and $H_{M}$ as explained in the unsubsidized case. We observe that the provision of subsidy has effect on retail advertising. This is obvious with the presence of $G_{M}$ in (17) which is not present in the unsubsidized case (9). This shows that the retail advertising is not only influenced by the rate of growth of the payoff of the retailer, but also by the subsidy from the manufacturer. Thus as the manufacturer's payoff increases, the subsidy to the retailer increases, and the retail advertising effort also increases.

From (19) we have that

$\lambda=\frac{2 G_{M}-G_{R}}{2 G_{M}+G_{R}}$.
This means that for $\lambda$ to be positive, $2 G_{M}>G_{R}$.

\section{Comparing the advertising efforts for subsidized and unsubsidized retail advertising}

We shall let $(\lambda=0)$ and $(\lambda>0)$ to be used as subscript and superscript to denote situation not involving subsidy and situation involving subsidy, respectively. It is pertinent to note that the retailer will accept subsidy from the manufacturer only if it will lead to an increase in his payoff or at worst let the payoff remain unchanged. As such we have that

$V^{R(\lambda>0)}(y) \geq V^{R(\lambda=0)}(y)$,

so that

$H_{R(\lambda>0)}+G_{R(\lambda>0)} y \geq H_{R(\lambda=0)}+G_{R(\lambda=0)} y$.

We also observe that with subsidy the rate of increase of the retailer's value function must be greater than his rate of increase without subsidy. At worst they must be equal. That is

$G_{R(\lambda>0)} \geq G_{R(\lambda=0)}$.

With subsidy much of the advertising burden is lifted from the manufacturer. Thus the manufacturer is no longer obliged to maintain the same level of advertising. Since increasing the manufacturer's advertising effort $a_{M}$ implies increasing the rate of increase of the payoff $G_{M}$, having provided subsidy leading to reduction in $a_{M}$, it equally follows that $G_{M}$ will reduce. Thus we have that

$G_{M(\lambda=0)} \geq G_{M(\lambda>0)}$.

However, we must have that

$V^{M(\lambda>0)} \geq V^{M(\lambda=0)}$,

else it is not worth subsidizing retail advertising.

We now consider the relationship between the advertising efforts for situations where retail advertising is subsidized and where it is not. Now, from (17) and (9) we have that

$$
\begin{aligned}
\frac{a_{R(\lambda>0)}(y)}{a_{R(\lambda=0)}(y)} & =\frac{\frac{\alpha\left(2 G_{M(\lambda>0)}+G_{R(\lambda>0)}\right) \sqrt{1-y}}{4}}{\frac{\alpha G_{R(\lambda=0)} \sqrt{1-y}}{2}} \\
& =\frac{\alpha\left(2 G_{M(\lambda>0)}+G_{R(\lambda>0)}\right)}{\alpha G_{R(\lambda=0)}} .
\end{aligned}
$$

Merging (26) with the fact that with subsidy $2 G_{M(\lambda>0)}>G_{R(\lambda>0)}$ we have that

$2 G_{M(\lambda>0)}>G_{R(\lambda>0)} \geq G_{R(\lambda=0)}$. 
Since

$G_{R(\lambda>0)} \geq G_{R(\lambda=0)}$,

we have that

$$
\begin{array}{r}
2 G_{M(\lambda>0)}+G_{R(\lambda>0)}>2 G_{R(\lambda=0)} \\
\Rightarrow \frac{a_{R(\lambda>0)}(y)}{a_{R(\lambda=0)}(y)}=\frac{\alpha\left(2 G_{M(\lambda>0)}+G_{R(\lambda>0)}\right)}{2 \alpha G_{R(\lambda=0)}}>1 \\
\Rightarrow a_{R(\lambda>0)}(y)>a_{R(\lambda=0)}(y) .
\end{array}
$$

Further from (10) and (18) we have that

$\frac{a_{M(\lambda>0)}(y)}{a_{M(\lambda=0)}(y)}=\frac{\frac{\alpha G_{M(\lambda>0)} \sqrt{1-y}}{2}}{\frac{\alpha G_{M(\lambda=0)} \sqrt{1-y}}{2}}=\frac{G_{M(\lambda>0)}}{G_{M(\lambda=0)}}$,

which from (27) leads to

$\frac{G_{M(\lambda>0)}}{G_{M(\lambda=0)}} \leq 1 \quad \Rightarrow a_{M(\lambda>0)}(y) \leq a_{M(\lambda=0)}(y)$.

From these we infer that while the subsidy from the manufacturer is enough motivation for the retailer to increase his advertising effort, his advertising effort is consequently reduced. Thus we conclude that:

\section{Theorem 5.1}

(i) The subsidized retail advertising effort is higher than the unsubsidized.

(ii) The manufacturer's participation in retail advertising leads to a reduced manufacturer's advertising effort.

\section{The evolution process of the awareness share}

It is necessary to specify the disturbance function so that the evolution process of the awareness share can be characterized. According to Prasad and Sethi (2004) and He et al. (2009) the disturbance function

$\sigma(y)=\sqrt{y(1-y)}$,

characterizes the evolution process of the awareness share. This is because it ensures that $y$ bounded between 0 and 1 irrespective of the stochastic disturbances.

Let $\{y(t) ; t \geq 0\}$ be one-dimensional for the Ito process given the stochastic differential equation

$\mathrm{d} y(t)=\mu_{*}(y(t), t) \mathrm{d} t+\mu_{* *}(y(t), t) \mathrm{d} z(t), y(0)=y_{0}$.

Observe that $y(t)$ is a Markov process (Cyganowski et al. 2002; He et al. 2011). In moving from awareness share $u$ at time 0 to awareness share $y$ at time $t>0$, the transition probability of this process $P(0, u ; t, x)$, satisfies the Fokker-Planck equation

$$
\begin{array}{r}
\frac{\partial}{\partial t} P(0, u ; t, x)=-\frac{\partial}{\partial u}\left(\mu_{*}(y(t), t) P(0, u ; t, y)\right) \\
+\frac{1}{2} \frac{\partial^{2}}{\partial u^{2}}\left(\left(\mu_{* *}(y(t), t)\right)^{2} P(0, u ; t, y)\right) \\
P(0, u ; t, y)=\delta(u-y) .
\end{array}
$$

Using (9) and (10) in (2) we have that

$$
\begin{aligned}
\mathrm{d} y(t)= & {\left[\frac{\alpha^{2}}{2}\left(G_{R}+G_{M}\right)-\left(\frac{\alpha^{2}}{2}\left(G_{R}+G_{M}\right)+k\right) y(t)\right] \mathrm{d} t } \\
& +\sigma \sqrt{y(1-y)} \mathrm{d} z(t) \\
& y(0)=y_{0}, \quad t \geq 0 .
\end{aligned}
$$

Equation (30) satisfies the Fokker-Planck equation

$$
\begin{aligned}
\frac{\partial}{\partial t} & P+\frac{\partial}{\partial u}\left(\left(\frac{\alpha^{2}}{2}\left(G_{R}+G_{M}\right)-\left(\frac{\alpha^{2}}{2}\left(G_{R}+G_{M}\right)+k\right) u\right) P\right) \\
& +\frac{1}{2} \frac{\partial^{2}}{\partial u^{2}}\left(\sigma^{2} u(1-u) P\right) \\
& =0
\end{aligned}
$$

Simplifying this and letting $P=f(u)$ for its density so that $\frac{\partial P}{\partial t}=0$, and then multiplying through by $\frac{2}{\sigma^{2}}$ we have the hypergeometric equation

$$
\begin{aligned}
u(u-1) \frac{\mathrm{d}^{2} f}{\mathrm{~d} u^{2}} & +\left(\left(4-\frac{2\left(\frac{\alpha^{2}}{2}\left(G_{R}+G_{M}\right)+k\right)}{\sigma^{2}}\right) u\right. \\
& \left.-\left(2-\frac{2 \frac{\alpha^{2}}{2}\left(G_{R}+G_{M}\right)}{\sigma^{2}}\right)\right) \frac{\mathrm{d} f}{\mathrm{~d} y} \\
& +\left(2-\frac{2\left(\frac{\alpha^{2}}{2}\left(G_{R}+G_{M}\right)+k\right)}{\sigma^{2}}\right) f=0 .
\end{aligned}
$$

The solution of this equation is

$f(u)=\frac{\Gamma\left(\frac{\alpha^{2}\left(G_{R}+G_{M}\right)+2 k}{\sigma^{2}}\right)}{\Gamma\left(\frac{\alpha^{2}\left(G_{R}+G_{M}\right)}{\sigma^{2}}\right) \Gamma\left(\frac{2 k}{\sigma^{2}}\right)} u^{\frac{\alpha^{2}\left(G_{R}+G_{M}\right)-\sigma^{2}}{\sigma^{2}}}(1-u)^{\frac{2 k-\sigma^{2}}{\sigma^{2}}}$. is

Observe that the long-run equilibrium awareness share

$y_{(\lambda=0)}=\frac{\alpha^{2}\left(G_{R}+G_{M}\right)}{\alpha^{2}\left(G_{R}+G_{M}\right)+2 k}$.

Also putting (17) and (18) into (2) we have

$$
\begin{aligned}
\mathrm{d} y(t)= & {\left[\frac{\alpha^{2}}{4}\left(4 G_{M}+G_{R}\right)-\left(\frac{\alpha^{2}}{4}\left(4 G_{M}+G_{R}\right)+k\right) y(t)\right] \mathrm{d} t } \\
& +\sigma \sqrt{y(t)(1-y(t))} .
\end{aligned}
$$


Substituting the term in the square bracket in (33) for that in the square bracket in (30) and proceeding as above, we have that

$f(u)=\frac{\Gamma\left(\frac{\alpha^{2}}{\sigma^{2}}\left(4 G_{M}+G_{R}\right)+\frac{2 k}{\sigma^{2}}\right)}{\Gamma\left(\frac{\alpha^{2}}{\sigma^{2}}\left(4 G_{M}+G_{R}\right)\right) \Gamma\left(\frac{2 k}{\sigma^{2}}\right)} u^{\frac{\alpha^{2}\left(4 G_{R}+G_{M}\right)-\sigma^{2}}{\sigma^{2}}}(1-u)^{\frac{2 k-\sigma^{2}}{\sigma^{2}}}$,

and the long-run awareness share is given by

$y_{(\lambda>0)}=\frac{\alpha^{2}\left(4 G_{R}+G_{M}\right)}{\alpha^{2}\left(4 G_{R}+G_{M}\right)+2 k}$.

From the discussions above we have the following results:

\section{Theorem 6.1}

(i) Suppose the manufacturer does not subsidise retail advertising, then the stationary distribution of awareness share is given by (31) and the longrun awareness share is given by (32)

(ii) Suppose the manufacturer subsidises retail advertising, then the stationary distribution of awareness share is given by (34) and the long-run awareness share is given by (35)

\section{Numerical results and discussion}

\section{Choice of parameter values}

Observe that $\alpha \in[0,1]$ reflect the effect of advertising on sale. We set it at 0.6. In our model the finite decay term which originated from Vidale and Wolfe (1957) and the positive discount rate can be adjusted to capture how important the present is with respect to the future. If the discount rate is high, then the firm effectively behaves like a myopic firm, and if it is low, like a foresighted firm. Thus, setting these two parameters high will make our work look like a static analysis. However, their being in the work helps us to explain dynamic implications. It is obvious that $\alpha$ must be greater than $k$ if advertising is to yield any positive result. If the rate of effectiveness is lower than that of decay, then it will be futile effort advertising. In consonance with the view that advertising is effective enough, $k$ is set low enough. Thus we have that $\alpha>k=0.2$. Since the game is played on an infinite horizon, and our firm is foresighted the discount rate is set very low. We take this to be $\eta=0.05$. Next we consider the players' profit margins per item sold. We take $M_{R}=45$ and $M_{M}=50$.

\section{Effect of subsidy on the players' advertising efforts}

We observe from Figs. 1 and 3 that without subsidy the manufacturer advertises more than the retailer. But with the provision of subsidy the order changed. We infer that with additional spending through subsidy, the manufacturer opts out of aggressive advertising to reduce expenditure. Thus subsidy is not out of place because the retailer is closer to the consumers. Also the channel effort is higher with subsidy as shown in Figs. 2 and 4.

\section{Comparison of the awareness shares for subsidised and unsubsidised retail advertising}

The primary purpose of advertising is to increase demand. This is achieved with increase in the market share. From Fig. 5 we observe that with subsidy, the awareness is higher. This results from aggressive retail advertising approach as can be seen in (17) when compared with (9). Looking at (32) we observe the effect of subsidy in (35) as shown in Fig. 5.

\section{The effect of subsidy on payoffs}

Let us now consider the effect of subsidy on players' payoffs. From (20) and (21) it is clear that the increase in the awareness share resulting from subsidy affects the players' payoffs. This is clear from Figs. 6 and 8. We also observe that the individual increase in the payoffs subsequently increases the channel payoff. Thus with subsidy the channel performs better. These are clear in Figs. 7 and 9

\section{Conclusion remarks}

The central aim of this work is to develop and use cooperative advertising models to consider the effect of subsidy on the players' advertising efforts; to consider the effect of these efforts on the awareness share, and then, the payoffs. These were achieved in this work.

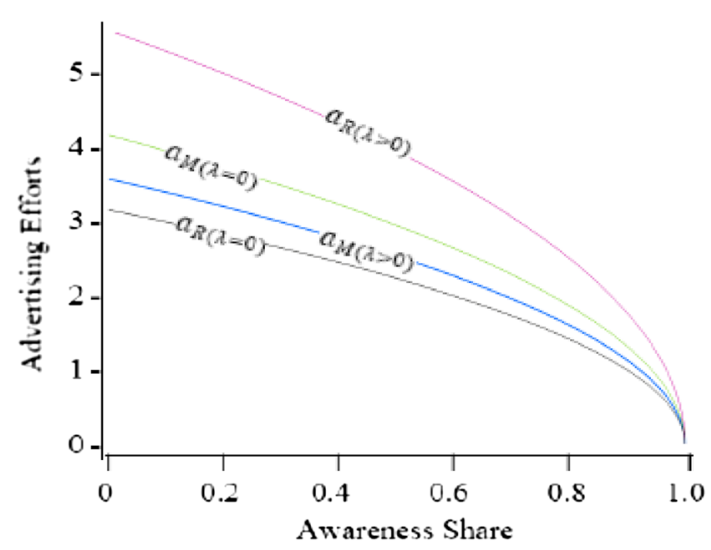

Fig. 1 A comparison of the players' advertising efforts using the awareness share 


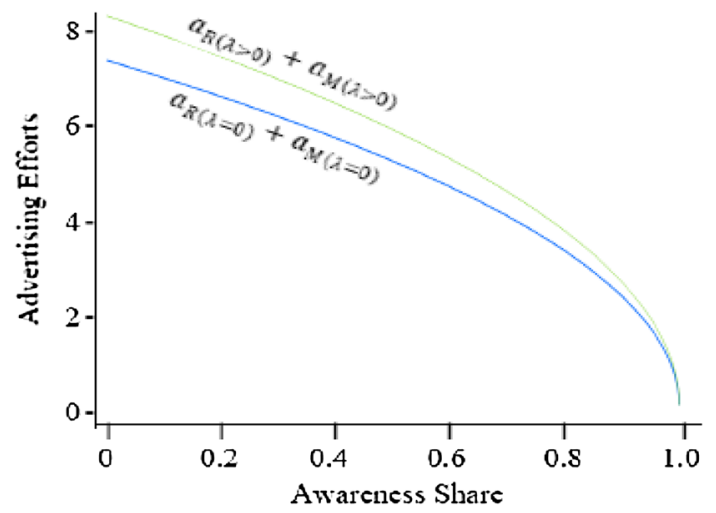

Fig. 2 A comparison of channel advertising efforts using the awareness share

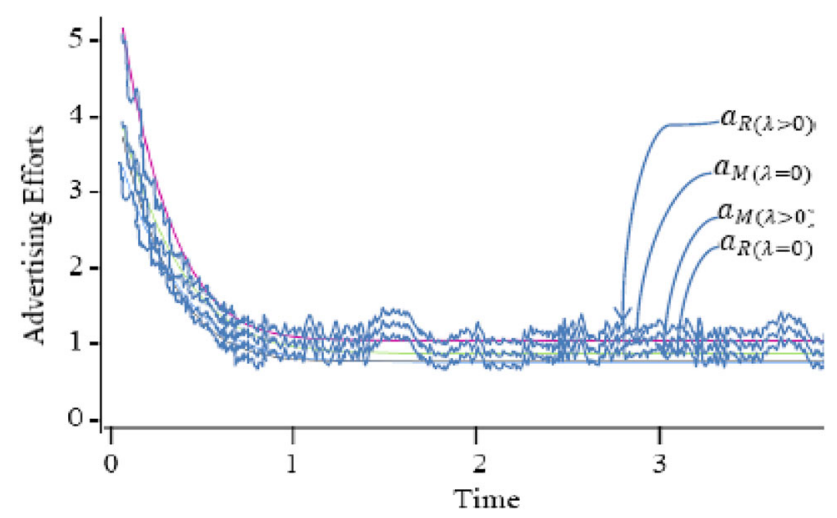

Fig. 3 A comparison of the players' advertising efforts using time

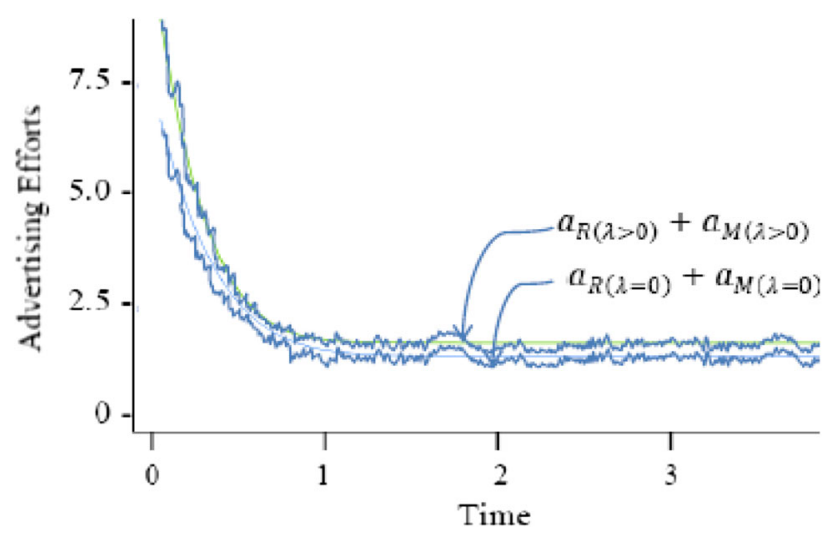

Fig. 4 A comparison of channel advertising efforts using time

Unlike a lot of works in the literature which consider cases where only one of the players (particularly the retailer) is directly involved in advertising, this work incorporates the manufacturer's national advertising into Sethi model. It then considered a situation where both players are involved in advertising, with the manufacturer involved in national advertising and the retailer in local

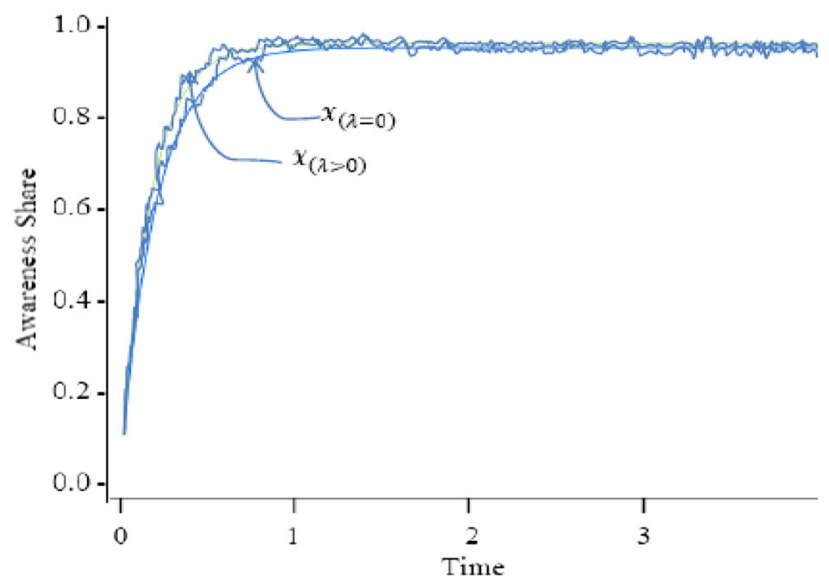

Fig. 5 A comparison of the awareness share for subsidised and unsubsidised advertising

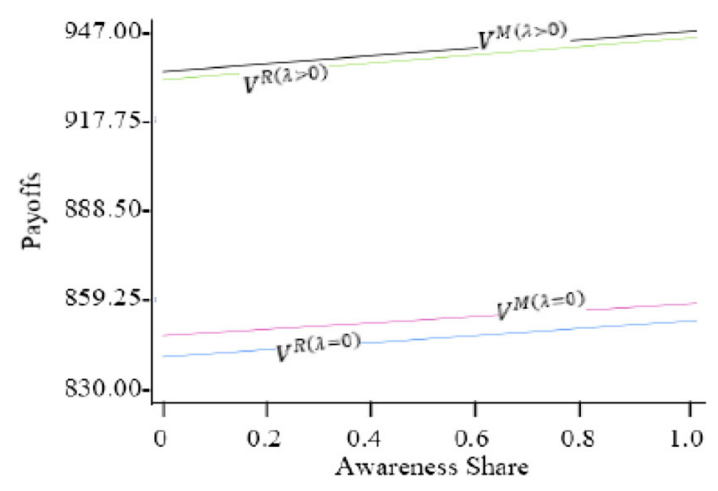

Fig. 6 A comparison of the players' payoffs using the awareness share

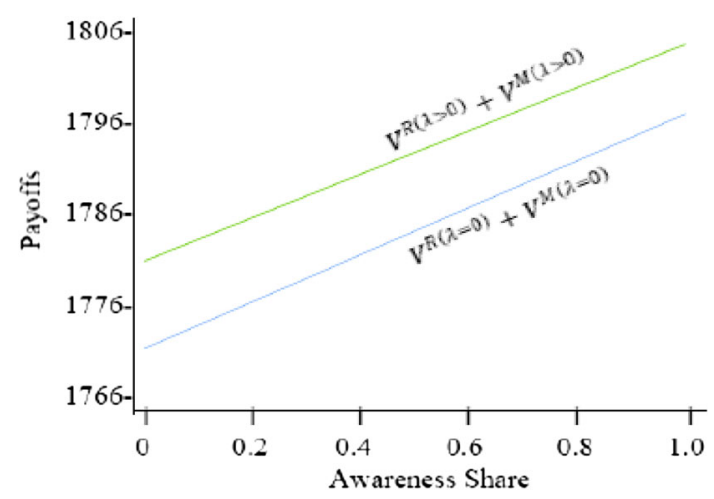

Fig. 7 A comparison of channel payoffs using the awareness share

advertising. We identified two types of equilibria. While one centred on unsubsidised retail advertising effort, the other majored on subsidized advertising. We obtained results which established how the advertising efforts affect the payoffs through the awareness share. The obtained 


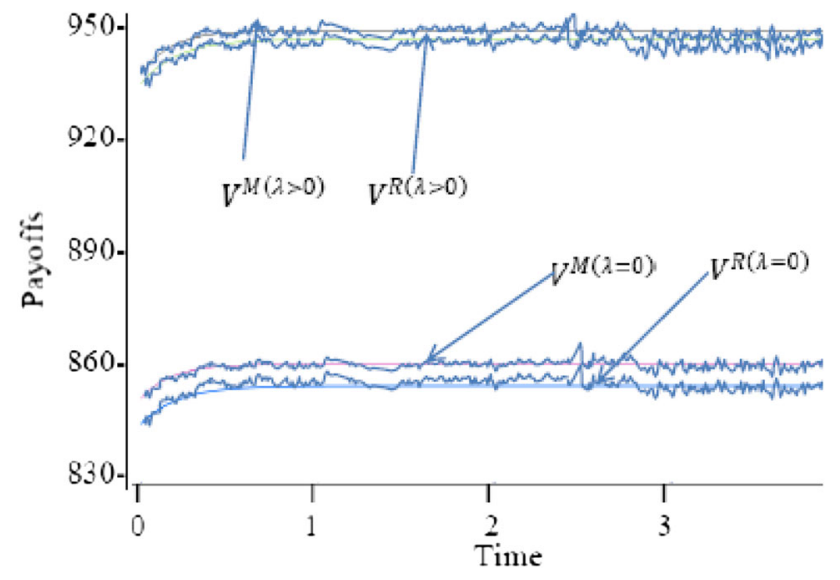

Fig. 8 A comparison of the players' payoffs using time

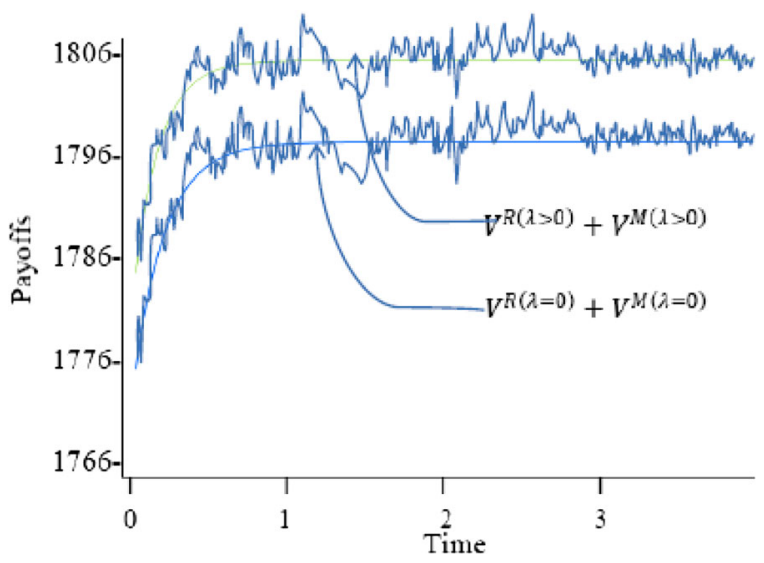

Fig. 9 A comparison of channel payoffs using time

strategies provide information on the extent that the firms should be involved in advertising. While the retailer should increase advertising with subsidy, the manufacturer should reduce advertising since his subsidy to the retailer is an involvement in advertising. Thus without much spending on brand name and goodwill (national advertising) his product can still be successfully sold by subsidising retail advertising.

The obtained long-run awareness shares inform the firms of the maximum possible awareness attainable. Thus it would be needless spending with the aim of exceeding the maximum level attainable. Any additional spending after attaining this level would amount to waste since that level cannot be exceeded.

The knowledge of the subsidy shows that the manufacturer should only support advertising when the rate of increase of his payoff is greater than half the rate of increase of the retailer's payoff.
This work has certain limitations. First, we assumed a bilateral monopolistic situation. This can be extended to a situation where there is competition between a number of manufacturers, retailers or both. Secondly, we considered a situation where the manufacturer is the Stackelberg leader. This work can be extended to consider a situation where the retailer is powerful enough to influence the manufacturer and act as the Stackelberg leader. Further, this work can be extended to consider an integrated channel structure where a Nash game is played by the manufacturer and the retailer. Such an extension can be used to compare the channel structures and determine which channel performs better.

Open Access This article is distributed under the terms of the Creative Commons Attribution 4.0 International License (http://crea tivecommons.org/licenses/by/4.0/), which permits unrestricted use, distribution, and reproduction in any medium, provided you give appropriate credit to the original author(s) and the source, provide a link to the Creative Commons license, and indicate if changes were made.

\section{Appendix 1}

\section{Proof of Theorem 3.1}

From (2) and (3) we have the Hamilton-Jacobi-Bellman (HJB) equation

$$
\begin{aligned}
\eta V^{R}= & \max _{a_{R}(t) \geq 0}\left\{M_{R} y-(1-\lambda(y)) a_{R}(t)^{2}\right. \\
& \left.+V_{y}^{R}\left[\alpha\left(a_{R}+a_{M}\right) \sqrt{1-y}-k y\right]+\frac{\sigma(y)^{2} V_{y y}^{R}}{2}\right\} .
\end{aligned}
$$

Maximizing wrt $a_{R}$ we have

$a_{R}\left(y \mid P_{M}, \lambda, a_{M}\right)=\frac{V_{y}^{R} \alpha \sqrt{1-y}}{2(1-\lambda(y))}$.

Now putting (36) in (37) we have

$$
\begin{aligned}
\eta V^{R}= & M_{R} y-\frac{\left(V_{y}^{R}\right)^{2} \alpha^{2}(1-y)}{2(1-\lambda(y))}+V_{y}^{R} \alpha a_{M} \sqrt{1-y}-V_{y}^{R} k y \\
& +\frac{\sigma(y)^{2} V_{y y}^{R}}{2} .
\end{aligned}
$$

Using (37) in (4) and (5) we have the HJB equation

$$
\begin{aligned}
& \eta V^{M}(y)=\max _{a_{M}(t) \geq 0,}\left\{M_{M} y-\lambda\left(\frac{V_{y}^{R} \alpha \sqrt{1-y}}{2(1-\lambda(y))}\right)^{2}\right. \\
& 0 \leq \lambda(t) \leq 1 \\
& \left.-a_{M}^{2}+V_{y}^{M}\left[\left(\frac{V_{y}^{R} \alpha \sqrt{1-y}}{2(1-\lambda(y))}+\alpha a_{M}\right) \sqrt{1-y}-k y\right]+\frac{\sigma(y)^{2} V_{y y}^{M}}{2}\right\} .
\end{aligned}
$$


Maximizing wrt $a_{M}$ we have

$$
a_{M}=\frac{V_{y}^{M} \alpha \sqrt{1-y}}{2} \text {. }
$$

Putting (40) into (39) we have

$$
\begin{aligned}
\eta V^{M}= & M_{M} y-\frac{\lambda\left(V_{y}^{R}\right)^{2} \alpha^{2}(1-y)}{4(1-\lambda)^{2}}+\frac{V_{y}^{M} V_{y}^{R} \alpha^{2}(1-y)}{2(1-\lambda)} \\
& +\frac{\left(V_{y}^{M}\right)^{2} \alpha^{2}(1-y)}{4} \\
& -V_{y}^{M} k y+\frac{\sigma(y)^{2} V_{y y}^{M}}{2} .
\end{aligned}
$$

Now, maximizing (41) with respect to $\lambda$ we obtain

$$
\begin{aligned}
& -\frac{\left(V_{y}^{R}\right)^{2} \alpha^{2}(1-y)}{4}\left[\frac{(1-\lambda)^{2}+2 \lambda(1-\lambda)}{(1-\lambda)^{4}}\right] \\
& \quad+\frac{V_{y}^{M} V_{y}^{R} \alpha^{2}(1-y)}{2(1-\lambda)^{2}} \\
& \quad=0
\end{aligned}
$$

which on simplification leads to (8).

\section{Appendix 2}

\section{Proof of Theorem 4.1}

Since there is no subsidy we have that $\lambda=0$. Thus, (6) becomes

$a_{R}^{*}(y)=\frac{V_{y}^{R} \alpha \sqrt{1-y}}{2}$.

Putting (36) and $\lambda(y)=0$ in (38) and (41) we have

$$
\begin{aligned}
\eta V^{R}(y)= & M_{R} y+\frac{\left(V_{y}^{R}\right)^{2} \alpha^{2}(1-y)}{4}+\frac{\alpha^{2} V_{y}^{R} V_{y}^{M}(1-y)}{2} \\
& -V_{y}^{R} k y+\frac{\sigma(y)^{2} V_{y y}^{R}}{2}
\end{aligned}
$$

and

$$
\begin{aligned}
\eta V^{M}(y)= & M_{M} y+\frac{\alpha^{2} V_{y}^{R} V_{y}^{M}(1-y)}{2}+\frac{\alpha^{2}\left(V_{y}^{M}\right)^{2}(1-y)}{4} \\
& -V_{y}^{M} k y+\frac{\sigma(y)^{2} V_{y y}^{M}}{2} .
\end{aligned}
$$

We use the approach of Sethi (1983) and He et al. (2009) to obtain linear value functions which work for our model. Thus let

$V^{R}(y)=H_{R}+G_{R} y$

and

$V^{M}(y)=H_{M}+G_{M} y$.

These imply that

$V_{y}^{M}=G_{M}$ and $V_{y}^{R}=G_{R}$.

Using (48) in (43) and (40) we have (9) and (10), respectively

Putting (46) and (48) into (44) we have

$$
\begin{aligned}
\rho\left(H_{R}+G_{R} y\right)= & M_{R} y-\frac{G_{R}^{2} \alpha^{2}(1-y)}{4}-\frac{\alpha^{2} G_{R} G_{M}(1-y)}{2} \\
& -G_{R} k y .
\end{aligned}
$$

Equating the coefficients of $y$ and constants, we have (13) and (15), respectively.

Also, putting (47) and (48) into (45) we have

$$
\eta\left(H_{M}+G_{M} y\right)=M_{M} y+\frac{\alpha^{2} G_{R} G_{M}(1-y)}{2}+\frac{\alpha^{2} G_{M}^{2}(1-y)}{4}
$$$$
-G_{M} k y \text {. }
$$

Equating the coefficients of $y$ and constants, we have (14) and (16), respectively.

Since there is no subsidy we have that $\lambda=\frac{2 V_{y}^{M}-V_{y}^{R}}{2 V_{y}^{M}+V_{y}^{R}} \leq 0 \quad \Rightarrow 2 V_{y}^{M}-V_{y}^{R} \leq 0 \quad \Rightarrow 2 G_{M} \leq G_{R}$.

\section{Appendix 3}

\section{Proof of Theorem 4.2}

When subsidy is given by the manufacturer, we have that $\lambda>0$. Now, from (48), we have that (37) becomes

$a_{R}^{*}(y)=\frac{\alpha\left(2 V_{y}^{M}+V_{y}^{R}\right) \sqrt{1-y}}{4}$.

Using (8) and (40) in (38) and (41) we have

$$
\begin{aligned}
\eta V^{R}(y)= & M_{R} y+\frac{\alpha^{2} V_{y}^{R}(1-y)\left(2 V_{y}^{M}+V_{y}^{R}\right)}{8} \\
& +\frac{\alpha^{2} V_{y}^{R} V_{y}^{M}(1-y)}{2}-V_{y}^{R} k y+\frac{\sigma(y)^{2} V_{y y}^{R}}{2}
\end{aligned}
$$

and 


$$
\begin{gathered}
\eta V^{M}(y)=M_{M} y-\frac{\alpha^{2}\left(\left(2 V_{y}^{M}\right)^{2}-\left(V_{y}^{R}\right)^{2}\right)(1-y)}{16} \\
+\frac{\alpha^{2} V_{y}^{M}\left(2 V_{y}^{M}+V_{y}^{R}\right)(1-y)}{4} \\
+\frac{\alpha^{2}\left(V_{y}^{M}\right)^{2}(1-y)}{4}-V_{y}^{M} k y+\frac{\sigma(y)^{2} V_{y y}^{M}}{2}
\end{gathered}
$$

Let

$$
\begin{aligned}
& V^{R}(y)=H_{R}+G_{R} y, \\
& V^{M}(y)=H_{M}+G_{M} y,
\end{aligned}
$$

so that

$V_{y}^{R}=G_{R} \quad$ and $\quad V_{y}^{M}=G_{M}$.

Using (54) in (49) and (40) we have (17) and (18), respectively.

Since subsidy is given by the manufacturer we have that

$$
\begin{aligned}
& 0<\lambda=\frac{2 V_{y}^{M}-V_{y}^{R}}{2 V_{y}^{M}+V_{y}^{R}}<1 \quad \Rightarrow 2 V_{y}^{M}-V_{y}^{R}>0 \quad \text { and } \\
& 2 V_{y}^{M}-V_{y}^{R}<2 V_{y}^{M}-V_{y}^{R} \Rightarrow 2 G_{M}>G_{R}>0 .
\end{aligned}
$$

In essence, $G_{R}$ is bounded. It is controlled by market forces.

Putting (52) and (54) into (50) we have that

$$
\begin{aligned}
8 \eta H_{R}+8 \eta G_{R} y= & 8 M_{R} y+2 \alpha^{2} G_{R} G_{M}+\alpha^{2} G_{R}^{2}-2 \alpha^{2} G_{R} G_{M} y \\
& -\alpha^{2} G_{R}^{2} y+4 \alpha^{2} G_{R} G_{M}-4 \alpha^{2} G_{R} G_{M} y \\
& -8 G_{R} k y .
\end{aligned}
$$

Equating the coefficients of $y$ and constants, we have (22) and (24), respectively.

Also putting (53) and (54) into (51), we have that

$$
\begin{aligned}
16 \eta H_{M}+16 \eta G_{M} y= & 16 M_{M} y-4 \alpha^{2} G_{M}^{2}+\alpha^{2} G_{R}^{2}+4 \alpha^{2} G_{M}^{2} y \\
& -\alpha^{2} G_{R}^{2} y+8 \alpha^{2} G_{M}^{2}+4 \alpha^{2} G_{M} G_{R} \\
& -8 \alpha^{2} G_{M}^{2} y-4 \alpha^{2} G_{M} G_{R} y+4 \alpha^{2} G_{M}^{2} \\
& -4 \alpha^{2} G_{M}^{2} y-16 G_{M} k y .
\end{aligned}
$$

Equating the coefficients of $y$ and constants, we have (23) and (25), respectively.

\section{References}

Aust G (2015) Vertical cooperative advertising in supply chain management: a game-theoretic analysis. Springer International Publishing, Switzerland

Basar T, Olsder GJ (1999) Dynamic noncooperative game theory. SIAM, Philadelphia, PA

Bass FM, Krishnamoorthy A, Prasad A, Sethi SP (2005) Generic and brand advertising strategies in a dynamic duopoly. Mark Sci 24(4):556-568
Berger PD (1972) Vertical cooperative advertising ventures. J Mark Res 9(3):309-312

Chintagunta PK, Jain DC (1992) A dynamic model of channel member strategies for marketing expenditures. Mark Sci 11(2):168-188

Chintagunta PK, Jain DC (1995) Empirical analysis of a dynamic duopoly model of competition. $\mathrm{J}$ Econ Manage Strat 4(1):109-131

Chintagunta PK, Vilcassim NJ (1992) An empirical investigation of advertising strategies in a dynamic duopoly. Manag Sci 38(9):1230-1244

Chintagunta PK, Vilcassim NJ (1994) Marketing investment decisions in a dynamic duopoly: a model and empirical analysis. Int $\mathrm{J}$ Res Mark 11(3):287-306

Cyganowski S, Kloeden P, Ombach J (2002) From elementary probability to stochastic differential equations with MAPLE. Springer, Berlin

Dant RP, Berger PD (1996) Modeling cooperative advertising decisions in franchising. J Oper Res Soc 47(9):1120-1136

Deal KR (1979) Optimizing advertising expenditures in a dynamic duopoly. Oper Res 27(4):682-692

Erickson GM (2009) An oligopoly model of dynamic advertising competition. Eur J Oper Res 197:374-388

Esmaeili M, Bahrini A, Shayanrad S (2015) Using game theory approach to interpret stable policies for Iran's oil and gas common resources conflicts with Iraq and Qatar. J Ind Eng Int 11(4):543-554

Esmaeilzadeh A, Taleizadeh AA (2016) Pricing in a two-echelon supply chain with different market powers: game theory approaches. J Ind Eng Int 12(1):119-135

Fruchter GE, Kalish S (1998) Dynamic promotional budgeting and media allocation. Eur J Oper Res 111(1):15-27

Gihman II, Skorohod AV (1972) Stochastic differential equations. Springer, New York

Giri BC, Bardhan S, Maiti T (2015) Coordinating a two-echelon supply chain with price and promotional effort dependent demand. Int J Oper Res 23(2):181-199

Golrizgashti S (2014) Supply chain value creation methodology under BSC approach. J Ind Eng Int 10:67

He X, Prasad A, Sethi SP (2009) Cooperative advertising and pricing in a dynamic stochastic supply chain: feedback stackelberg strategies. Prod Oper Manag 18(1):78-94

He X, Krshnamoorthy A, Prasad A, Sethi SP (2011) Retail competition and cooperative advertising. Oper Res Lett 39:11-16

He Y, Liu Z, Usman K (2014) Coordination of cooperative advertising in a two-period fashion and textiles supply chain. Math Probl Eng. doi:10.11552/2014/356726

Heydari J, Norouzinasab Y (2015) A two-level discount model for coordinating a decentralized supply chain considering stochastic price-sensitive demand. J Ind Eng Int 11(4):531-542

Houk B (1995) Co-op advertising. NTC Publishing, Lincolnwood, Illinois

Huang Z, Li SX, Mahajan V (2002) An analysis of manufacturerretailer supply chain coordination in cooperative advertising. Decis Sci 33(3):469-494

Jørgensen S, Sigue SP, Zaccour G (2000) Dynamic cooperative advertising in a channel. J Retail 76(1):71-92

Jørgensen S, Taboubi S, Zaccour G (2003) Retail promotions with negative brand image effects: is cooperation possible? Eur $\mathrm{J}$ Oper Res 150(2):395-405

Karray S, Zaccour G (2005) A differential game of advertising for national brand and store brands. In: Haurie A, Zaccour G (eds) Dynamic games: theory and applications. Springer, Berlin, pp 213-229 
Kumar S, Luthra S, Haleem A (2013) Customer involvement in greening the supply chain: an interpretive structural modeling methodology. J Ind Eng Int 9:6

Little JDC (1979) Aggregate advertising models: the state of the art. Oper Res 27(4):629-667

Mahmoudi R, Hafezalkotob A, Makui A (2014) Source selection problem of competitive power plants under government intervention: a game theory approach. J Ind Eng Int 10:59

Naik PA, Raman K, Winer R (2005) Planning marketing-mix strategies in the presence of interactions. Mark Sci 24(1):25-34

Naik PA, Prasad A, Sethi SP (2008) Building brand awareness in dynamic oligopoly markets. Manag Sci 54(1):129-138

Nerlove MK, Arrow J (1962) Optimal advertising policy under dynamic conditions. Economica 29:129-142

Prasad A, Sethi SP (2004) Competitive advertising under uncertainty: a stochastic differential game approach. J Optim Theory Appl 123(1):163-185

Prasad A, Sethi SP (2009) Integrated marketing communications in markets with uncertainty and competition. Automatica 45(3):601-610

Rao KN, Subbaiah KV, Singh GVP (2013) Design of supply chain in fuzzy environment. J Ind Eng Int 9:9
Sethi SP (1983) Deterministic and stochastic optimization of a dynamic advertising model. Optim Control Appl Methods 4(2):179-184

Sorger G (1989) Competitive dynamic advertising: a modification of the case game. J Econ Dyn Control 13:55-80

Taleizadeh AA, Charmchi M (2015) Optimal advertising and pricing decisions for complementary products. $J$ Ind Eng Int 11(1):111-117

Tull DS, Wood VR, Duhan D, Gillpatrick T, Robertson KR, Helgeson JG (1986) "Leveraged" decision making in advertising: the flat maximum principle and its implications. J Mark Res 23(1):25-32

Vidale ML, Wolfe HB (1957) An Operations Research study ofsales response to advertising. Oper Res 5(3):370-381

Young R, Greyser SA (1983) Managing cooperative advertising: a strategic approach. Lexington Books, Lanham

Yue J, Austin J, Wang M, Huang Z (2006) Coordination of cooperative advertising in a two-level supply chain when manufacturer offers discount. Eur J Oper Res 168:65-85 